\title{
Erratum to: NTBC Treatment of the Pyomelanogenic Pseudomonas aeruginosa Clinical Isolate PA1111 Inhibits Pigment Production and Increases Sensitivity to Oxidative Stress
}

Laura M. Ketelboeter • Vishwakanth Y. Potharla •

Sonia L. Bardy

Published online: 7 November 2014

(c) Springer Science+Business Media New York 2014

Erratum to: Curr Microbiol (2014) 69:343-348

DOI 10.1007/s00284-014-0593-9

In the original version of this article, there was error in the authors' names. Now, the authors' names are listed correctly.

The online version of the original article can be found under doi:10.1007/s00284-014-0593-9. 